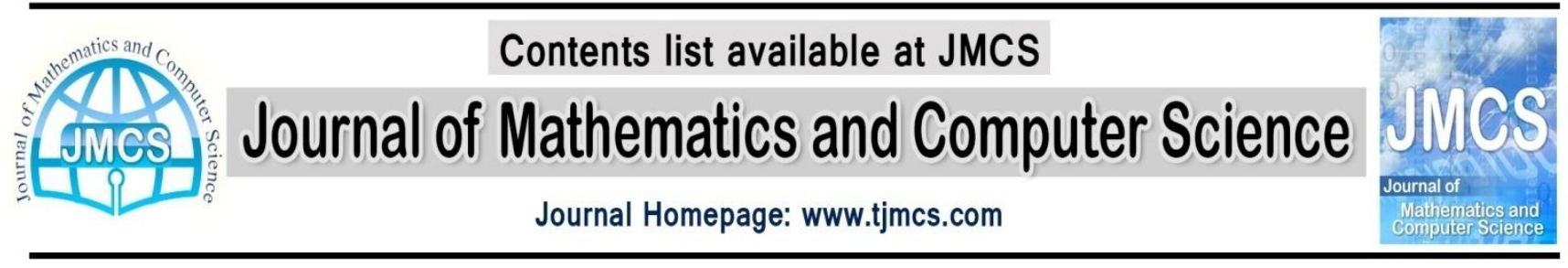

\title{
Design Fuzzy Controller for Synthesis Water Level
}

\author{
Seyed Kamaleddin Mousavi Mashhadi \\ School of Electrical Engineering, Iran University of Science and Technology, Tehran, Iran \\ Sk_mousavi@iust.ac.ir \\ Elham Sareban \\ Faculty of Electrical Engineering, Khorasan Institute of Higher Education, Mashhad, Iran

\section{Elham.Sareban@gmail.com} \\ Amir Aminian \\ Faculty of Electrical Engineering, Khorasan Institute of Higher Education, Mashhad, Iran \\ Amir.Aminian7sh@gmail.com
}

Article history:

Received October 2013

Accepted December 2013

Available online December 2013

\begin{abstract}
The purpose of this paper is the design of fuzzy control for the synthesis water level control system. At first we design classical PID controller and then compare with Sugeno and Mamdani type of new investigated fuzzy logic controller (FLC). Finally, used regression analysis for implementation of designed fuzzy controller in practice. Simulation results show the ability of designed controller and regression analysis as practical method for implementation of this controller.
\end{abstract}

Keywords: PID controller, Fuzzy control system, Synthesis water level, Regression analysis.

\section{Introduction}

Nowadays, the various parameters in the process of industrial are controlled such as temperature, level. The level control is a type of control method for common in process 
system. The synthesis water level control system must be controlled by the proper controller. The objective of the controller in the level control is to maintain a level set point at a given value and be able to accept new set point values dynamically. Fuzzy logic represents soft computing method for solving problems where classical logic cannot provide satisfying results. The Mamdani control rules are significantly more linguistically intuitive while Sugeno rules appear to have more interpolation power even for a relative small number of control rules. The controller designed using fuzzy logic implements human reasoning that has been programmed into fuzzy logic language (membership functions, rules and the rules interpretation)It is interesting to note that the success of fuzzy logic control is largely due to the awareness to its many industrial applications [1]. Industrial interests in fuzzy logic control as evidenced by the many publications on the subject in the control literature has created an awareness of its interesting importance by the academic community [2]. In [3] Sugeno fuzzy model as the model structure for a linear model based predictive control of the liquid level. In [4] adaptive model-reference fuzzy controller for controlling the water level in a water tank. The simplified of the level control system is shown in Figure 1.

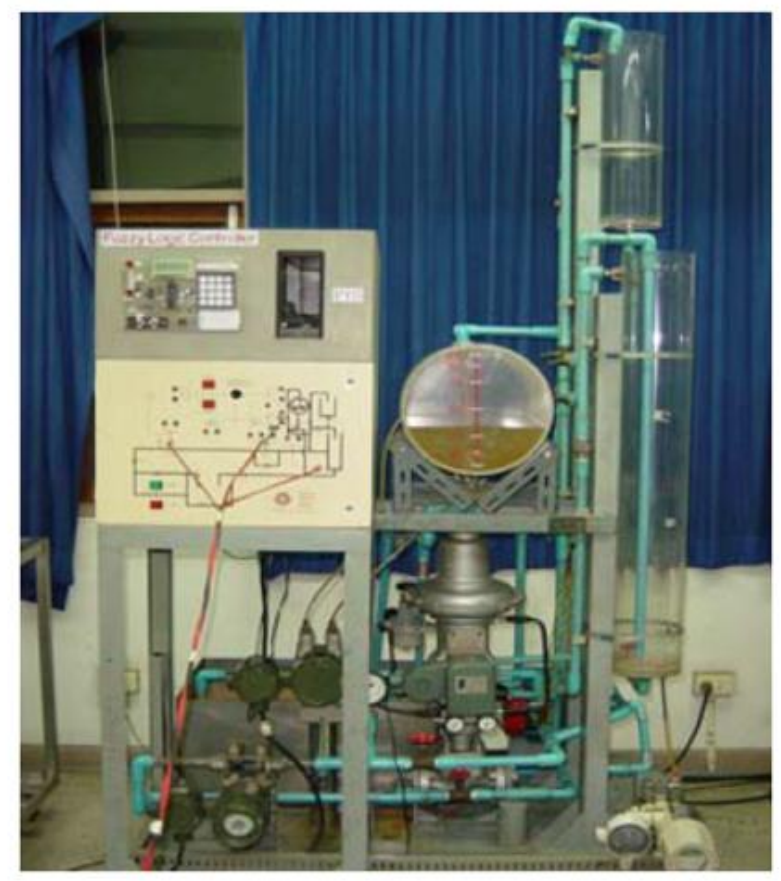

Figure 1. Plant level control set up [5]

In this paper, two different methods regarding the tuning at conventional classic PID and fuzzy logic controller has been presented. The purpose of this paper is designing the fuzzy controller for controlling water level system by Mamdani and Sugeno models. Performance of the fuzzy logic controller was evaluated and compared with a conventional PID controller. We have shown that the effect of operating temperature on the system output 
due to the better outcome is achieved. Simulation results investigate with root mean squared error (RMSE).

\section{Plants Model}

The general model is suggested as follows [5]:

$F(s)=1 /\left(25 s^{2}+5 s+1\right)$

Where:

$\mathrm{F}(\mathrm{s}):$ transfer function

$\mathrm{S}$ : Operator

The first entry in the fuzzy controller Mamdani and Sugeno is represented linguistic variable E, which write with the equation:

$E=K_{p} \cdot(W-X)$

Where:

$\mathrm{E}[\mathrm{V}]$ : control error (in the fuzzy controller input)

$\mathrm{W}[\mathrm{V}]$ : desired value of controlled variable

$\mathrm{X}[\mathrm{V}]$ : $\quad$ actual (measured) value of controlled variable

$\mathrm{K}_{\mathrm{p}}$ : $\quad$ proportional gain, constant

The two input in the fuzzy controller Mamdani and Sugeno is represented linguistic variable DE, which was written by the equation:

$D E=K_{d} \cdot(d E / d t)$

Where:

$\mathrm{DE}[\mathrm{V} / \mathrm{s}]$ time derivative of regulating tolerance

$\mathrm{E}[\mathrm{V}]$ : control error

$\mathrm{t}[\mathrm{s}]: \quad$ time

$\mathrm{K}_{\mathrm{d}}$ : differential gain

Other input in the fuzzy controller is represented linguistic variable $\mathrm{T}$. 


\section{Design Classical PID controller}

Classical PID controllers are the most popular and widely-used controllers in industry. The most industrial process can be controlled with PID control. PID controllers are widely used in process control industry due to relatively simple structure and easiness in implementation. Because of their simplicity, robustness and successful practical application that can provide excellent control performance despite the varied dynamic characteristics of plant. We designed a classical PID controller [6]. Figure 2 is the structural block diagram of the PID controller. We conducted synthesis (simulation) PID controller with three input linguistic variables (E; control error, DE; outflow regulating tolerance, T; temperature) and two output linguistic variable and Heater (Y; valve position in volts, $\mathrm{H}$; Heater). In the classical regulator we are changing the gain factor $\left(\mathrm{K}_{\mathrm{p}}\right.$; proportional gain, a tuning parameter $\mathrm{K}_{\mathrm{d}}$; differential gain, a tuning parameter $\mathrm{K}_{\mathrm{i}}$; integral gain, a tuning parameter). Figures 3 and 4 respectively have shown the step response and error tracking of input command with the PID controller. Controller transfer function is:

$\mathrm{P}_{\mathrm{PID}}=\mathrm{K}_{\mathrm{p}}\left(1+\frac{1}{s T_{i}}+\frac{s T_{d}}{1+s / p d}\right)$

The PID controller parameters are given table 1.

Table 1. Parameters of PID controller

\begin{tabular}{|c|c|}
\hline $\mathrm{K}_{\mathrm{p}}$ & 2.15 \\
\hline $\mathrm{K}_{\mathrm{I}}$ & $0.268 / \mathrm{s}$ \\
\hline $\mathrm{K}_{\mathrm{D}}$ & $4.32 * \mathrm{~s}$ \\
\hline
\end{tabular}

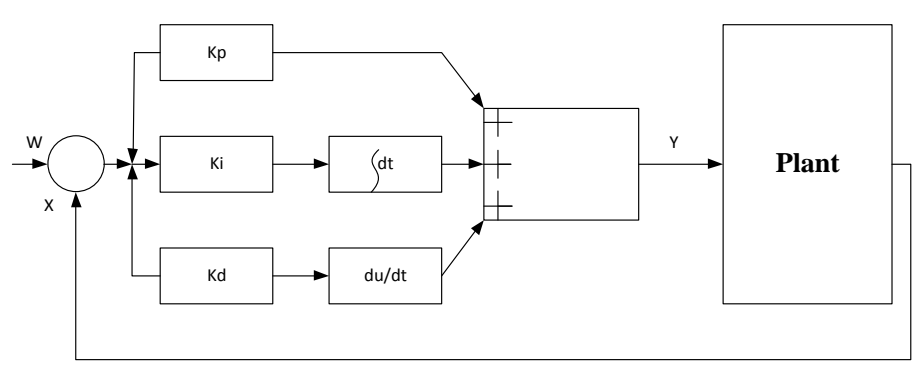

Figure 2. Liquid level model process with classical PID controller 


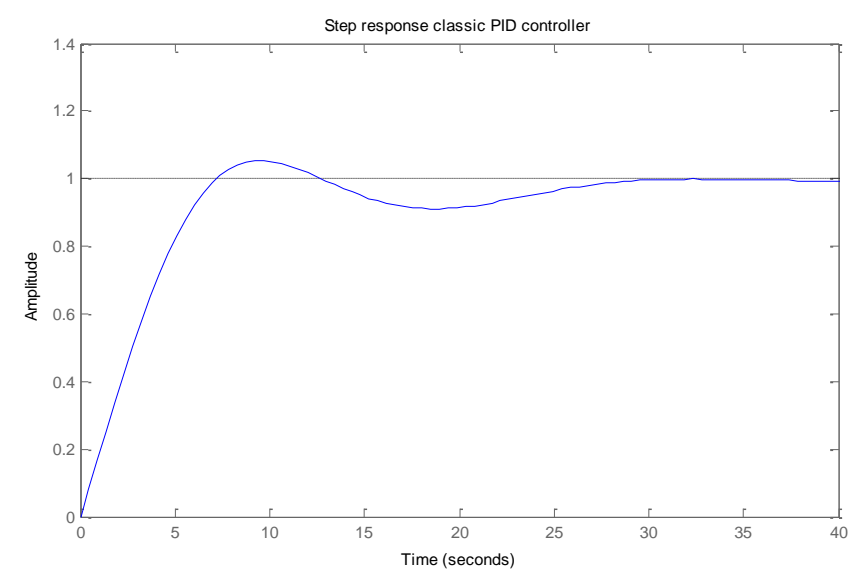

Figure 3. Step response classical PID controller

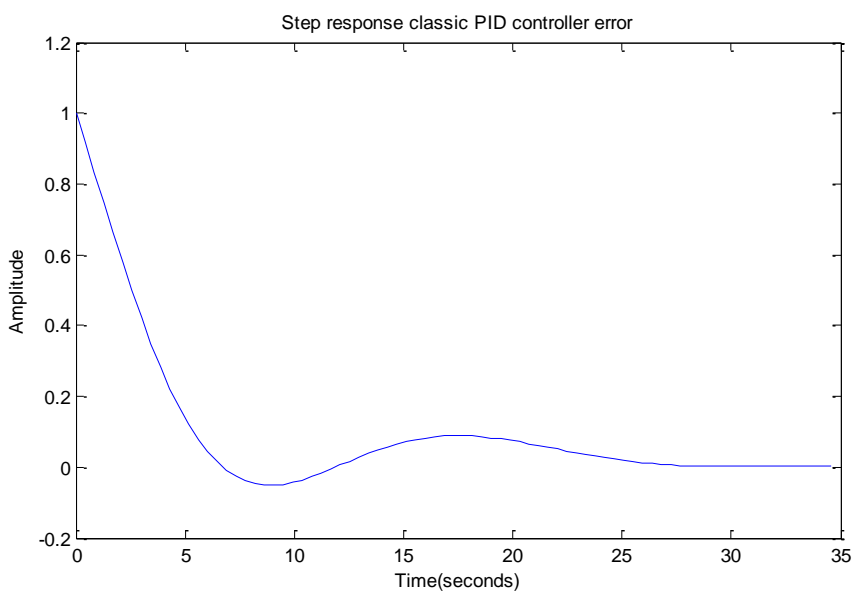

Figure 4. Error of tracking step command in classic PID controller

\section{Design Fuzzy controller}

A fuzzy logic model is a logical-mathematical procedure based on a "IF-THEN" rule system that allows for the reproduction of the human way of thinking in computational form [7]. The most widespread methodologies for developing fuzzy rule systems are those proposed by Mamdani and Sugeno [8]. The Mamdani method (FL-M) follows exactly the above mentioned scheme, whereas the Takagi-Sugeno method (FL-TS) uses a composite procedure for fuzzy inference and output defuzzification. In this study, both methods are used for developing two different forecasting models [9]. In fuzzy control, two controllers for the system are chosen. Input controllers are an error (E), an error derivative (DE) and Temperature (T). Linguistic variables (E, DE, T and Y, H) we with FIS tools described by five membership functions triangular and Gaussian (Figures 5, 6, 7, 8 and 9). 


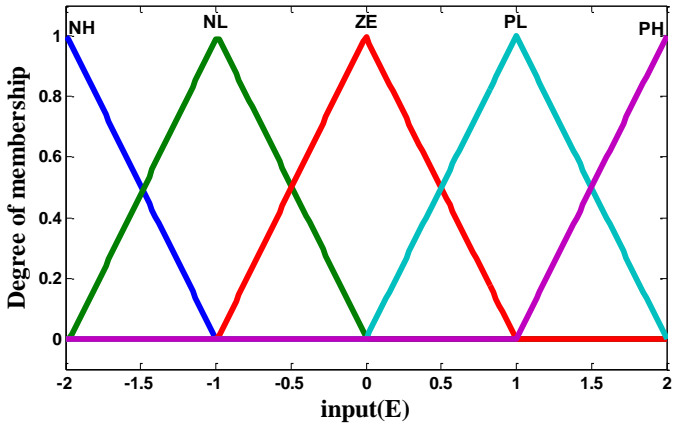

Figure 5. Membership functions for input $E$

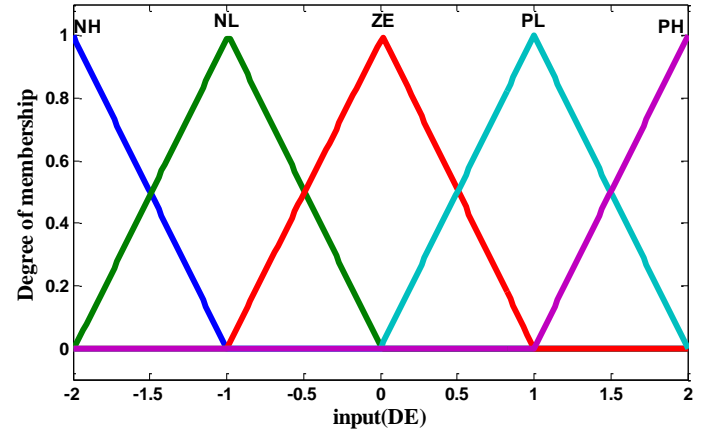

Figure 6. Membership functions for input DE

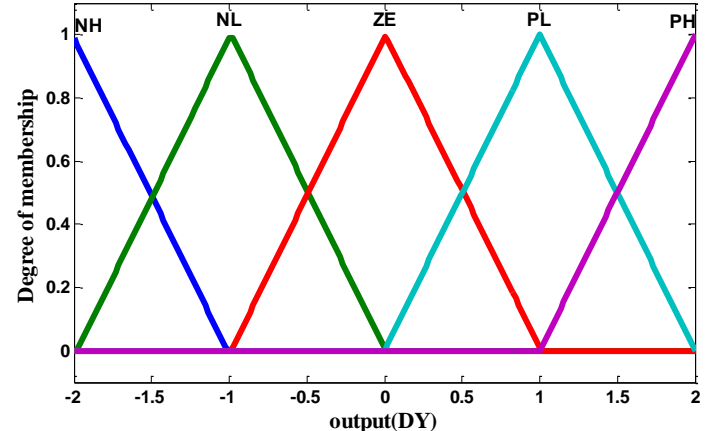

Figure 7. Membership functions for output $Y$

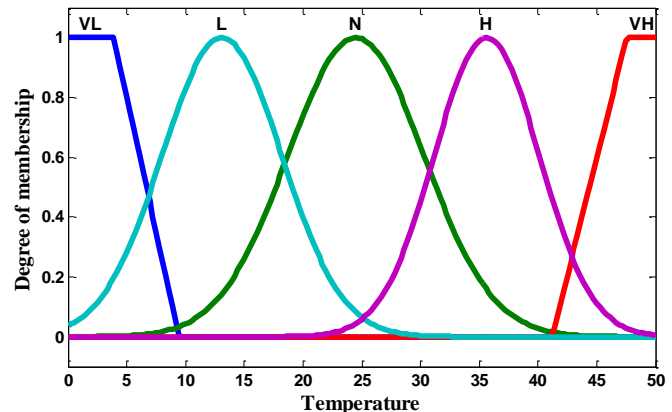

Figure 8. Membership functions for input Temperature 


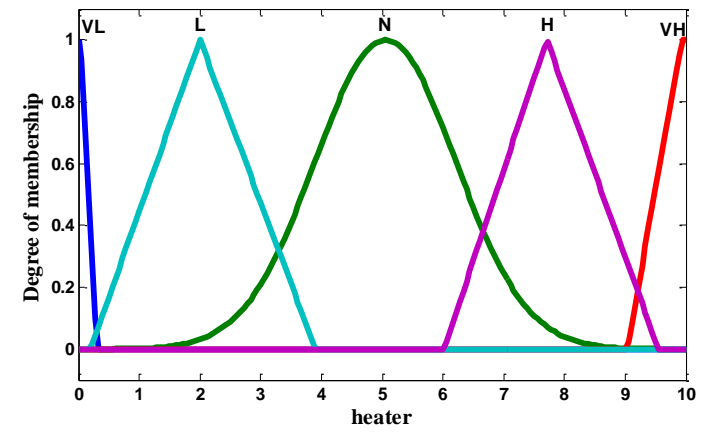

Figure 9. Membership functions for output Heater

Membership functions were presented with linguistic values described in Table 2. After completing the process of softening the three inputs and one output linguistic variable we continued with the inference process (decision making). The procedure was performed so that we write a set of rules in a matrix format (Table 3 and 4).

Language description of the system (fuzzy controller), we have made with shape rules "IFTHEN". We have 25 rules for control y and 10 rules for control $\mathrm{H}$, entered into the tool FIS. As a result of implementing fuzzy rules among input and output functions, one would be directed to figures 10, 11 and 12. Looking at these diagrams is advantageous to regulate and correct input/output functions more simply and also to modify fuzzy rules once needed. As can be seen, they do demonstrate a relatively smooth behavior instead of a sharp rise.

Table 2. Description of the rate of linguistic value membership fuzzy controller

\begin{tabular}{|c|c|}
\hline Linguistic Value in the FIS & The rate of linguistic values \\
\hline NH & Negative high \\
\hline NL & Negative little \\
\hline ZE & Nothing \\
\hline PL & Positive little \\
\hline PM & Positive many \\
\hline
\end{tabular}


Table 3. Basic rules table for Mamdani and Sugeno system

\begin{tabular}{|c|c|c|c|c|c|c|}
\hline \multirow{2}{*}{$\begin{array}{c}\text { OUTPUT } \\
(Y)\end{array}$} & & \multicolumn{5}{|c|}{ INPUT (E) } \\
\cline { 2 - 7 } & & NH & NM & ZE & PL & PM \\
\hline \multirow{4}{*}{$\begin{array}{c}\text { INPUT } \\
(\mathrm{DE})\end{array}$} & $\mathrm{NH}$ & $\mathrm{NH}$ & $\mathrm{NH}$ & $\mathrm{NH}$ & $\mathrm{NL}$ & $\mathrm{ZE}$ \\
\cline { 2 - 7 } & $\mathrm{NL}$ & $\mathrm{NH}$ & $\mathrm{NH}$ & $\mathrm{NL}$ & $\mathrm{ZE}$ & $\mathrm{PL}$ \\
\cline { 2 - 7 } & $\mathrm{ZL}$ & $\mathrm{NH}$ & $\mathrm{NL}$ & $\mathrm{ZE}$ & $\mathrm{PL}$ & $\mathrm{PM}$ \\
& & $\mathrm{PL}$ & $\mathrm{ZE}$ & $\mathrm{PL}$ & $\mathrm{PL}$ & $\mathrm{PM}$ \\
& $\mathrm{PM}$ & $\mathrm{ZE}$ & $\mathrm{PL}$ & $\mathrm{PM}$ & $\mathrm{PM}$ & $\mathrm{PM}$ \\
\hline
\end{tabular}

Table 4. The set of Temperature rules

\begin{tabular}{|c|c|c|c|c|c|}
\hline INPUT(Temperature) & VL & $\mathrm{N}$ & VH & L & H \\
\hline OUTPUT(heater) & VH & $\mathrm{N}$ & OFF & H & L \\
\hline
\end{tabular}

In the language of controllers for the first rule that means: if the desired value differs significantly from the measured value (liquid level) and the difference between the two further declines with high liquid level, then the control action must be high (valve should be fully open). After the establishment of control rules in the matrix form, we designed a fuzzy control algorithm, called the inference. Inference we designed from the rules control the use of inference operators. With the help of inference rules we establish in the crowd (Tables 3 and 4) fuzzy output crowd. In the application we used Mamdani inference operator, with whom we have formed membership functions sets of rules (all rules), based on output. Mamdani inference operator we set in the tool FIS.

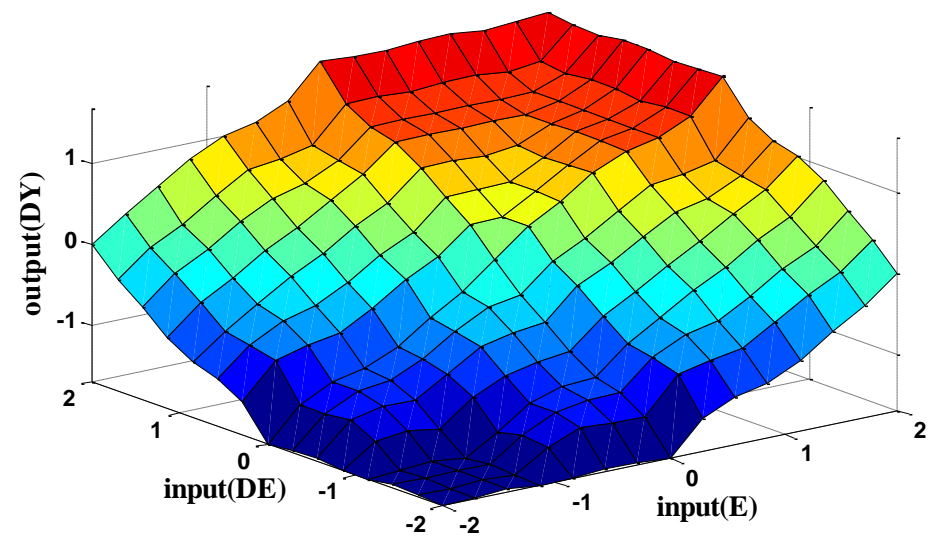

Figure 10. 3D surface of $E$ and DE inputs with Mamdani 


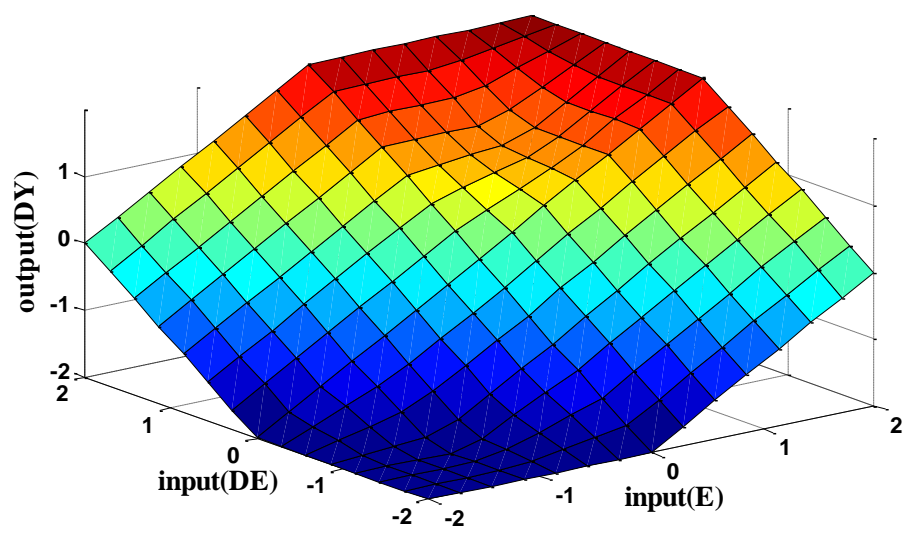

Figure 11. 3D surface of $E$ and $D E$ inputs with Sugeno

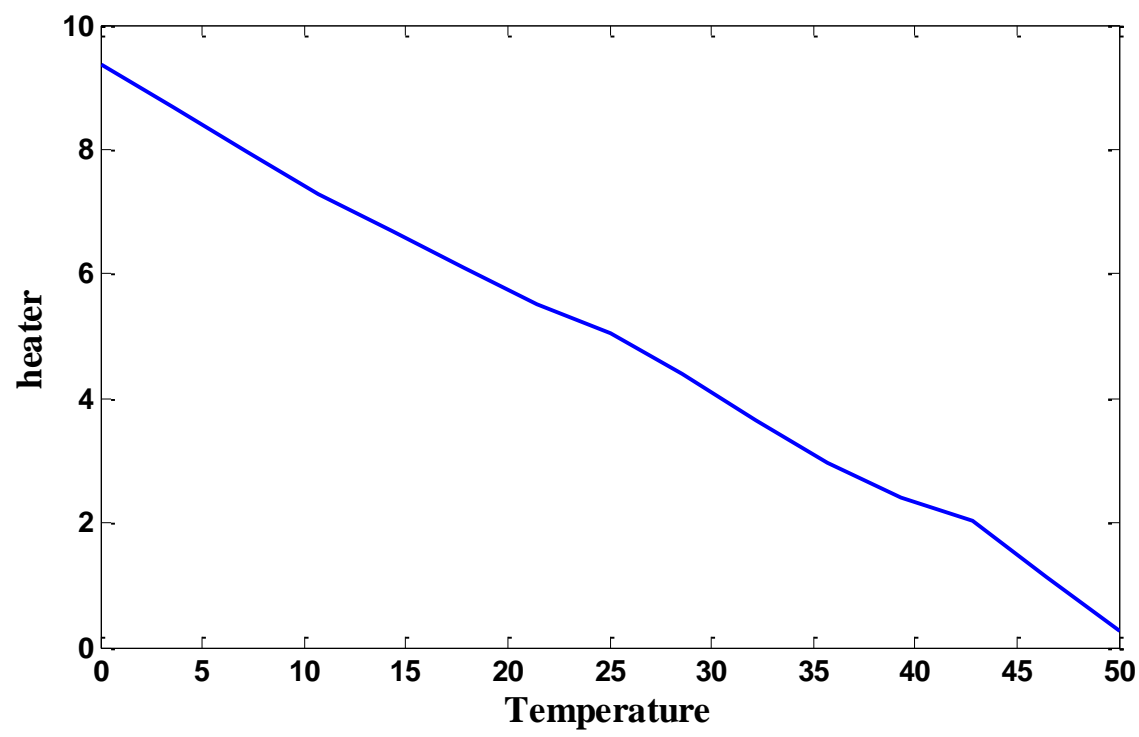

Figure 12. Surface of Temperature input

\section{Fuzzy regression model}

Regression analysis is used in evaluating the functional relationship between the dependent and independent variables and also in determining the best-fit model for describing the relationship. In the usual conventional model, deviations between the observed values and the estimated values are supposed to be due to measurement errors or random variations. Therefore, the statistical techniques are applied for estimation and inference in regression analysis. But sometimes the deviations are due to the imprecise observed data or the indefiniteness of the system structure. In this case, the uncertainty is not due to randomness but fuzziness. Regression 
analysis on fuzzy data in dealing with fuzziness is usually called fuzzy regression analysis. General fuzzy regression model takes the form:

$$
\tilde{Y}=f(X, \tilde{A})=\tilde{A}_{1} X_{1}+\tilde{A}_{2} X_{2}+\ldots+\tilde{A}_{n} X_{x}
$$

Where $\tilde{Y}$ is the fuzzy output, ${ }_{n}$, is a fuzzy coefficient, and $\mathrm{X}=\left(\mathrm{X}_{1}, \ldots, \mathrm{X}_{\mathrm{n}}\right)$ is an $\mathrm{n}$-dimensional non-fuzzy input vector.

Developing the fuzzy regression control gives an opportunity for samples to be expressed as fuzzy numbers. The fuzzy upper and lower control limits and center line are defined as fuzzy membership functions in a fuzzy regression control. These characteristics provide more accurate decisions on a sample when the sample mean is too close to the control limits and the measurement systems is not very sensitive.

\subsection{Result of fuzzy regression}

Fuzzy Regression equations have being attended due to many reasons. They easily enter mathematical operations and usually provide acceptable approximations for complex equations. Figures 13 shows 3D surface regression for the E, DE and T inputs and outputs. Figure 14 shows the fuzzy input and output temperature. The equation obtained with this estimates for the Mamdani and Sugeno models is given in Tables 5 and 6. In Table 7 compare the errors of the model Sugeno and Mamdani. Measure of mean squared error has been utilized in order to calculate the amount of output error produced from the functions of obtained equation and the desired fuzzy controller.

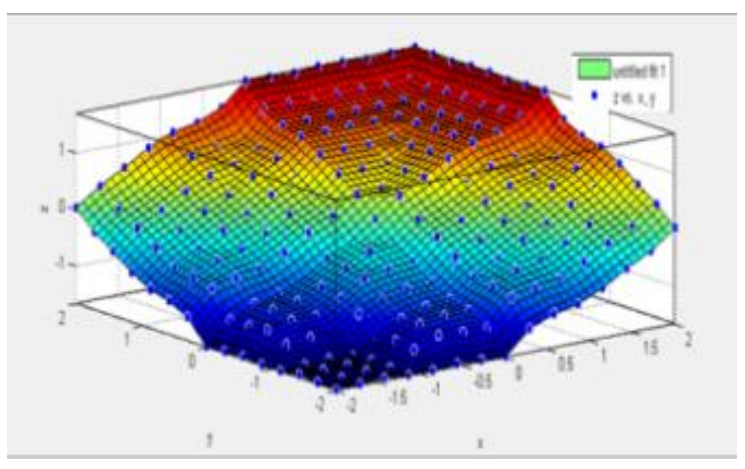

Figure 13. 3D surface of linear fuzzy regression for DE and $E$ inputs 


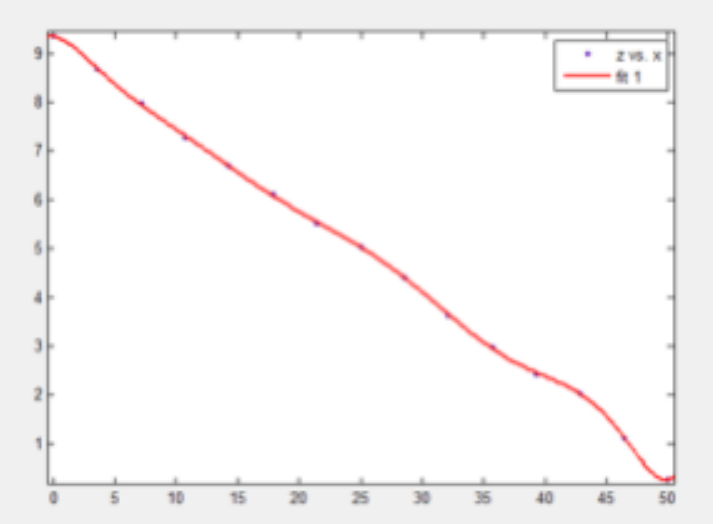

Figure 14. Surface of linear fuzzy regression for Temperature

Table 5. The linear fuzzy regression equation

\begin{tabular}{|c|c|}
\hline \multicolumn{1}{|c|}{ MAMDANI } & SUGENO \\
\hline Linear model Poly11: & Linear model Poly11: \\
$\mathrm{f}(\mathrm{x}, \mathrm{y})=\mathrm{p}_{00}+\mathrm{p}_{10} * \mathrm{x}+\mathrm{p}_{01} * \mathrm{y}$ & $\mathrm{f}(\mathrm{x}, \mathrm{y})=\mathrm{p}_{00}+\mathrm{p}_{10} * \mathrm{x}+\mathrm{p}_{01} * \mathrm{y}$ \\
Coefficients (with 95\% confidence bounds): & Coefficients (with 95\% confidence bounds): \\
$\mathrm{p}_{00}=-0.03241(-0.06221,-0.002606)$ & $\mathrm{p}_{00}=-0.05345(-0.09125,-0.01564)$ \\
$\mathrm{p}_{10}=0.5736(0.5494,0.5977)$ & $\mathrm{p}_{10}=0.7329(0.7023,0.7635)$ \\
$\mathrm{p}_{01}=0.5721(0.5479,0.5962)$ & $\mathrm{p}_{01}=0.7345(0.7039,0.7651)$ \\
Goodness of fit: & Goodness of fit: \\
RMSE: 0.2268 & RMSE: 0.2878 \\
\hline
\end{tabular}

Table 6. The surface fuzzy regression equation

\begin{tabular}{|l|l|}
\hline $\begin{array}{l}\text { Linear model Poly9: } \\
\mathrm{f}(\mathrm{x})=\mathrm{p}_{1} * \mathrm{x}^{9}+\mathrm{p}_{2} * \mathrm{x}^{8}+\mathrm{p}_{3} * \mathrm{x}^{7}+\mathrm{p}_{4} * \mathrm{x}^{6}+\mathrm{p}_{5} * \mathrm{x}^{5}+\mathrm{p}_{6} * \mathrm{x}_{4}+\mathrm{p}_{7} * \mathrm{x}^{3}+ \\
\mathrm{p}_{8} * \mathrm{x}^{2}+\mathrm{p}_{9} * \mathrm{x}+\mathrm{p}_{10}\end{array}$ & \\
Coefficients (with 95\% confidence bounds): & \\
$\mathrm{p}_{1}=4.819 \mathrm{e}-012(1.757 \mathrm{e}-012,7.881 \mathrm{e}-012)$ & \\
$\mathrm{p}_{2}=-1.032 \mathrm{e}-009(-1.722 \mathrm{e}-009,-3.427 \mathrm{e}-010)$ & \\
$\mathrm{p}_{3}=9.168 \mathrm{e}-008(2.66 \mathrm{e}-008,1.568 \mathrm{e}-007)$ & \\
$\mathrm{p}_{4}=-4.374 \mathrm{e}-006(-7.71 \mathrm{e}-006,-1.037 \mathrm{e}-006)$ & \\
$\mathrm{p}_{5}=0.0001216(2.084 \mathrm{e}-005,0.0002224)$ & \\
\hline
\end{tabular}




$$
\begin{aligned}
& \mathrm{p}_{6}=-0.002003(-0.003819,-0.0001864) \\
& \mathrm{p}_{7}=0.01892(0.000113,0.03772) \\
& \mathrm{p}_{8}=-0.09172(-0.1923,0.008818) \\
& \mathrm{p}_{9}=-0.02307(-0.2356,0.1895) \\
& \mathrm{p}_{10}=9.349(9.251,9.448)
\end{aligned}
$$

Goodness of fit:

RMSE: 0.03821

Table 7. Comparison of regression errors

\begin{tabular}{|c|c|c|c|c|}
\hline $\mathrm{E}$ & DE & MAMDANI & SUGENO & $\begin{array}{c}\text { FUZZY } \\
\text { REGRESSION }\end{array}$ \\
\hline-2 & -1 & -1.68 & -2 & -1.78 \\
\hline-1 & 0 & -0.98 & -1 & -1 \\
\hline 0 & 0 & 0 & 0 & 0 \\
\hline 0 & 1 & 0.98 & 1 & 1 \\
\hline 1 & 2 & 1.68 & 2 & 1.79 \\
\hline
\end{tabular}

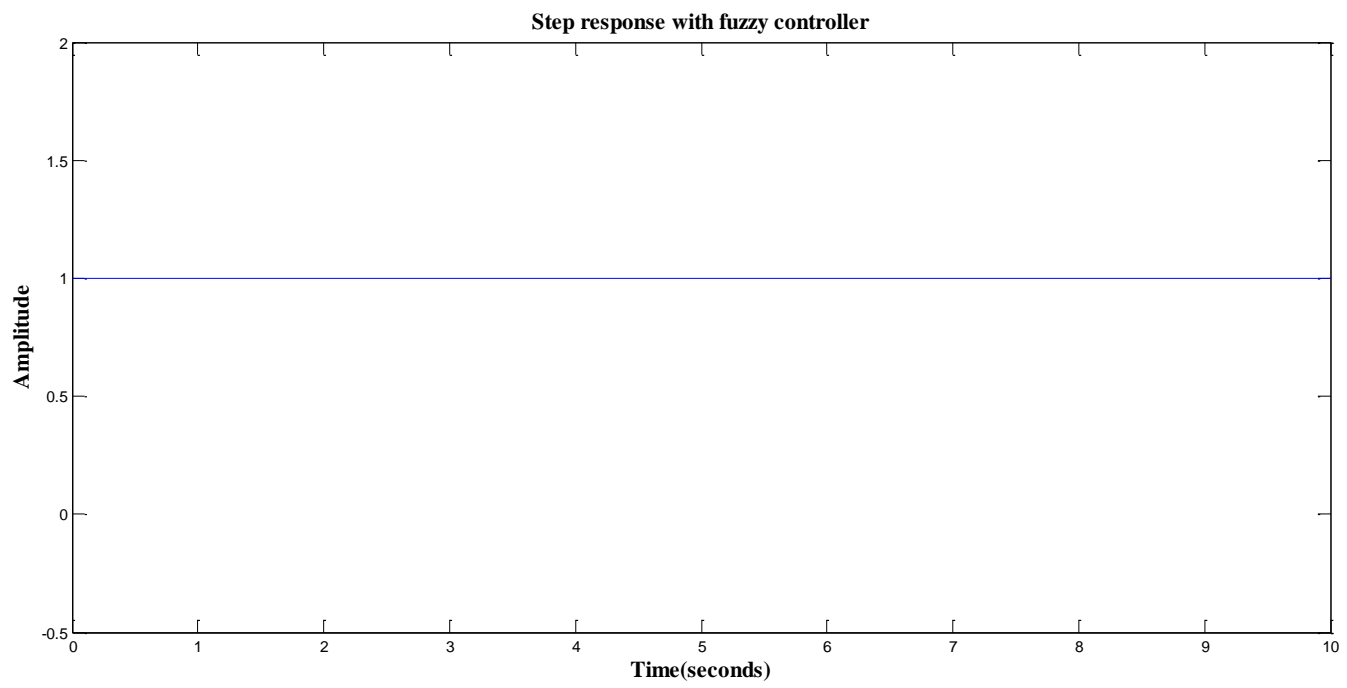

Figure 15. Step response using fuzzy logic controller 
Figure 15 showed the step response of the synthesis water level model with the fuzzy logic controller. As a result of comparing, fuzzy logic controller is superior to classic PID controller. Especially it can give more attention to various parameters, such as the time of response, the error of steadying and overshoot. Comparison of the control results from these two controllers indicated that the fuzzy controller significantly reduced overshoot and steady state error. In Table (8) compare the PID and FLC is shown.

Table 8. Comparison results of FLC and PID

\begin{tabular}{|c|c|c|}
\hline Parameters & FLC & PID \\
\hline Overshoot & Not Present & Present \\
\hline Settling Time & Less & More \\
\hline Transient & Not Present & Present \\
\hline Rise Time & Less & Present \\
\hline
\end{tabular}

\section{Conclusions}

In this paper, we investigate new fuzzy logic controller for synthesis water level control and compare the results with classical PID controller. Also regression analysis used for the practical method for implementation of the proposed fuzzy controller. Simulation results shown RMSE error of obtained model is acceptable and fuzzy logic controller has better performance in compare with PID controller.

\section{References}

[1] R.E. Precup, H. Hellendoorn, "A survey on industrial applications of fuzzy control”, Compuers in industry, pp. 213-226, 2011.

[2] Dharamniwas, A. Ahmad, V. Redhu, U. Gupta, "Liquid Level Control by using Fuzzy Logic Controller," International Journal of Advances in Engineering \& Technology, Vol. 4, No. 1, pp. 537-549, 2012.

[3] J.A. Roubos, R. Babuska, R.M. Bruijn, H.B. Verbruggen, "Predictive Control by Local Linearization of a Takagi-Sugeno Fuzzy Model,” IEEE Transactions, Vol. 1, pp. 37-42, 1998.

[4] A.T. Naman, M.Z. Abdulmuin, H. Arof, "Development and Application of a Gradient Descent Method in Adaptive Model Reference Fuzzy Control," TENCON Proceedings. Intelligent Systems and Technologies for the New Millennium, Vol. 3, pp. 358-363, 2000.

[5] P. Berk, D. Stajnko, P. Vindis, B. Mursec, M. Lakota, "Synthesis water level control by fuzzy logic," Journal of Achievements in Materials and Manufacturing Engineering, Vol. 45, No. 2, pp. 204-210, 2011. 
[6] L.A. Zadeh, "Outline of New Approach to the Analysis of Complex Systems and Decision Processes”, IEEE Transaction on Systems, Man and Cybernetics, Vol. 3, pp. 28-44, 1973.

[7] F.A. Salem, A.A. Rashed, "PID Controllers and Algorithms: Selection and Design Techniques Applied in Mechatronics Systems Design - Part II," International Journal of Engineering Sciences, Vol. 2, No. 5, pp. 191-203, 2013.

[8] E.H. Mamdani, "Application of Fuzzy Algorithm for Control of Simple Dynamic Plant," Proceedings of the Institution of Electrical Engineers, IEEE, Vol. 121, No. 12, pp. 1585-1888, 1974.

[9] T. Takagi, M. Sugeno, "Fuzzy identification of systems and its application to modeling and control,” IEEE Transactions on Systems, Vol. 15, No. 1, pp. 116-132, 1985. 